\title{
Daya Hambat Isolat Jamur Rizosfer Tanaman Kopi (Coffea sp.) Terhadap Pertumbuhan Jamur Penyebab Busuk Buah Kopi (Coffea sp.)
}

\section{(Inhibition Of The Coffee (Coffea Sp.)Plant Rhizosphere Fungus Isolate Against The Growth Of The Fungus That Causes Coffee (Coffea Sp.) Fruit Rot)}

\author{
Asna Lusiana Safitri ${ }^{1, *)}$, Mukarlinal), Zulfa Zakiah ${ }^{2}$ \\ 1) Universitas Tanjungpura; Jl. Prof. Dr. H. Hadari Nawawi, Pontianak, Kalimantan Barat, \\ Indonesia \\ 2)Program Studi Biologi, Jurusan Biologi FMIPA UNTAN Kalimantan Barat, 78124 \\ *Email korespondensi: mukarlina@fmipa.untan.ac.id
}

(Article History: Received Dec16, 2021; Revised Jan 20, 2022; Accepted Feb 2, 2022)

\begin{abstract}
Abstrak
Penyakit busuk buah pada tanaman kopi (Coffea sp.) disebabkan oleh jamur patogen (Fusarium sp.). Pengendalian penyakit busuk buah kopi dapat dilakukan dengan menggunakan agen hayati berupa jamur rizosfer yang memiliki sifat antagonis terhadap jamur patogen. Penelitian ini bertujuan untuk mengetahui jenis jamur dari busuk buah kopi dan jamur rizosfer serta untuk mengetahui kemampuan jamur rizosfer dalam menghambat pertumbuhan jamur patogen. Penelitian dilakukan pada bulan JanuariApril 2020. Penelitian ini menggunakan Rancangan Acak Lengkap (RAL) dengan 4 perlakuan dan 3 kali pengulangan. Pengambilan sampel dilakukan di perkebunan kopi (Coffea sp.) Desa Punggur Kecil Kabupaten Kubu Raya. Isolasi jamur dilakukan dengan metode pengenceran dan uji antagonis dilakukan dengan metode berpasangan. Berdasarkan hasil penelitian, terjadi penghambatan pertumbuhan jamur Fusarium sp. JPTK1 dan Fusarium sp. JPTK2 oleh Trichoderma sp. JRTK3 dengan persentase antagonis tertinggi masing-masing yaitu $37,12 \%$ dan $70,48 \%$.
\end{abstract}

Kata kunci: penyakit busuk buah; agen hayati; kopi; jamur rizosfer.

\begin{abstract}
Fruit rot disease in coffee plants (Coffea sp.) is caused by pathogenic fungi (Fusarium sp.). Control of coffee berry rot disease can be done by using biological agents in the form of rhizosphere fungi which have antagonistic properties against pathogenic fungi. This study aims to determine the type of fungus from coffee fruit rot and rhizosphere fungi and to determine the ability of rhizosphere fungi to inhibit the growth of pathogenic fungi. The study was conducted in January-April 2020. This study used a completely randomized design (CRD) with 4 treatments and 3 repetitions. Sampling was carried out in a coffee plantation (Coffea sp.) Punggur Kecil Village, Kubu Raya Regency. Fungal isolation was carried out using the dilution method and the antagonist test was carried out using the paired method. Based on the results of the study, there was an inhibition of the growth of the fungus Fusarium sp. JPTK1 and Fusarium sp. JPTK2 by Trichoderma sp. JRTK3 with the highest percentage of antagonists were $37.12 \%$ and $70.48 \%$, respectively.
\end{abstract}

Keywords: fruit rot disease; biological agents; coffee; rhizosphere fungi

\section{PENDAHULUAN}

Kopi (Coffea sp.) merupakan tanaman perkebunan yang mampu meningkatkan devisa negara. Saat ini Indonesia menjadi produsen utama kopi ketiga setelah Brazil dan
Vietnam. Kubu Raya merupakan salah satu Kabupaten yang memiliki perkebunan kopi terluas di Kalimantan Barat. Luas perkebunan kopi di Kabupaten Kubu Raya mencapai 5.369 ha, namun hasil 
produktivitasnya masih tergolong sangat rendah yaitu 0.200 ton/ha (Rudy 2014). Punggur merupakan salah satu desa di Kabupaten Kubu Raya yang masyarakatnya membudidayakan kopi. Pembudidayaan kopi dilakukan secara turun temurun dan dijadikan sebagai sumber penghasilan masyarakat setempat. Kendala dalam budidaya kopi disebabkan oleh penyakit yang menimbulkan gejala busuk pada buah kopi di Kabupaten Kubu Raya.

Cara pengendalian jamur patogen yang umumnya dilakukan oleh petani kopi di Kabupaten Kubu Raya menggunakan fungisida sintetik. Penggunaan fungisida sintetik diketahui kurang efektif. Fungisida sintetik memiliki dampak negatif jika digunakan secara terus menerus disebabkan residu yang tertinggal di dalam tanaman dan dapat membunuh spesies-spesies non target (Djafarudin, 2004 dan Soesanto 2008).

Alternatif pengendalian jamur patogen secara biologi dapat menggunakan jamur termasuk jamur di sekitar perakaran tanaman atau jamur rizosfer. Jamur rizosfer memiliki aktivitas antagonis terhadap jamur patogen dengan mekanisme hiperparasitisme dan antibiosis untuk membatasi pertumbuhan dan perkembangan jamur patogen (Soesanto 2008). Beberapa penelitian membuktikan bahwa jamur rizosfer mampu menghambat mikroorganisme patogen yang mengganggu tanaman. Penelitian Gilang (2015) membuktikan bahwa terdapat 3 genus jamur rizosfer tanaman kakao yang mampu menghambat pertumbuhan jamur patogen Phytophthora palmivora pada buah kakao. Genus-genus jamur tersebut adalah Aspergillus, Penicillium, dan Trichoderma.
Penelitian mengenai jamur rizosfer pada tanaman kopi di Indonesia sudah pernah dilakukan oleh Sari et al. (2013) namun pengendalian busuk buah kopi menggunakan jamur rizosfer belum pernah dilakukan di Indonesia. Sehingga perlu dilakukan penelitian agar masyarakat dapat menemukan solusi dalam menghambat dan menekan pertumbuhan jamur patogen penyebab busuk buah kopi yang mempengaruhi nilai produktivitas buah kopi di Indonesia.

Penelitian ini bertujuan untuk mengetahui jenis jamur dari busuk buah kopi dan jamur rizosfer tanaman kopi serta untuk mengetahui kemampuan jamur rizosfer dalam menghambat pertumbuhan jamur patogen.

\section{METODE}

Pengambilan sampel dilakukan pada pagi hari diperkebunan kopi di Desa Punggur Kecil Kecamatan Sungai Kakap Kabupaten Kubu Raya. Sampel rizosfer diambil dari tanah sekitar perakaran kopi yang sehat. Pengambilan sampel ditentukan secara acak pada 3 tanaman kopi dengan 3 kali pengulangan pada setiap tanaman kopi. Sampel buah kopi diambil sebanyak \pm 1 gram yang menunjukkan 2 jenis gejala penyakit busuk buah yang berbeda kemudian dimasukkan ke dalam kantong plastik.

Isolasi jamur rizosfer tanaman kopi dilakukan menggunakan metode pengenceran. Masing-masing sampel tanah dari 3 titik pengambilan sampel ditimbang sebanyak 1 gram dan dimasukkan ke dalam tabung reaksi yang telah berisi akuades sebanyak 9 $\mathrm{ml}$ dan dihomogenkan. Sampel tanah kemudian diencerkan hingga tingkat pengenceran $10^{-5}$. Hasil dari tiap-tiap pengenceran $10^{-3}, 10^{-4}$ dan $10^{-5}$ dipipet sebanyak $1 \mathrm{ml}$, kemudian 
dituang ke dalam media PDA dengan metode pour plate. Media yang telah padat diinkubasi pada suhu $28^{\circ} \mathrm{C}$ selama 7 hari (Fety et al. 2015).

Isolasi jamur busuk buah dari buah kopi dilakukan dengan metode pengenceran. Buah kopi yang busuk dicuci dengan deterjen cair, selanjutnya dicuci dengan air yang mengalir, kemudian dikeringkan anginkan di atas tisu steril. Sampel buah kopi yang bergejala busuk di potong-potong dengan ukuran $2-3 \mathrm{~cm}$. Buah kopi disterilkan menggunakan alkohol $70 \%$ selama 30 detik, kemudian direndam didalam larutan. $\mathrm{NaOCl} 1 \%$ selama 2 menit. Tahap selanjutnya buah kopi dicuci menggunakan akuades steril sebanyak 3 kali pengulangan (Fitriah et al. 2014).

Sampel buah kopi dihaluskan menggunakan mortar, kemudian ditimbang sebanyak 1 gram dan dimasukkan ke dalam tabung reaksi yang berisi air steril sebanyak $9 \mathrm{ml}$ dan dihomogenkan menggunakan vortex, pengenceran tersebut merupakan pengenceran $10^{-1}$, kemudian dilakukan cara yang sama sampai diperoleh pengenceran $10^{-3}$, masing-masing pengenceran diambil 1 $\mathrm{ml}$ dan dimasukkan ke dalam cawan petri dan dituang media PDA (Fitriah et al. 2014 dan Waluyo 2008).

Identifikasi berdasarkan karakter koloni secara makroskopis seperti warna koloni, bentuk tepian, diameter, bentuk koloni dan tekstur permukaan koloni. Pengamatan secara mikroskopis meliputi struktur hifa dan struktur reproduksi vegetatif. Identifikasi jamur mengacu pada buku A Guide to Tropical Fungi (Sutton 1990), Illustrated Genera of Imperfect Fungi (Barnett dan Hunter 1998), Pictorial Atlas of Soil and Seed Fungi (Watanabe 2002).
Uji antagonis secara in vitro dilakukan terhadap setiap jenis jamur yang ditemukan dari rizosfer tanaman kopi. Pengujian dilakukan dengan metode uji ganda. Biakan murni jamur busuk buah kopi dan jamur hasil isolasi dari rizosfer tanaman kopi masing-masing diambil spora dengan menggunakan jarum ose dan diinokulasikan pada cawan petri yang berisi media PDA. Perlakuan kontrol isolat jamur busuk buah kopi diinokulasikan ke permukaan media PDA pada bagian tengah. Kemudian diinkubasikan pada suhu $28^{\circ} \mathrm{C}$ selama tujuh hari (Rianti 2010).

Data yang diperoleh dalam penelitian ini disajikan dalam bentuk foto hasil pengamatan uji antagonis dan grafik diameter dari pertumbuhan nilai rata-rata jamur antagonis dengan jamur rizosfer. Data tabel diameter dari nilai rata-rata jamur antagonis dengan jamur rizosfer dari tanaman kopi pada pengukuran hari ke tujuh dianalisis menggunakan Analysis of Varians (ANOVA). Hasil yang beda nyata dilanjutkan dengan uji Duncan pada taraf kepercayaan 5\%.

\section{HASIL DAN PEMBAHASAN}

Hasil isolasi dari buah kopi bergejala busuk ditemukan 2 jenis jamur yaitu Fusarium sp. JPTK1 dan Fusarium sp. JPTK2 (Gambar 1). Ada 2 gejala busuk buah yang ditemukan di perkebunan kopi Punggur Kecil. Hasil isolasi jamur dari rizosfer tanaman kopi ditemukan 3 jenis jamur yaitu Aspergillus sp. JRTK1, Penicillium sp. JRTK2, dan Trichoderma sp. JRTK3 (Gambar 2).

Berdasarkan hasil uji antagonis jamur rizosfer terhadap jamur Fusarium sp. JPTK1, semua perlakuan antagonis jamur rizosfer tersebut dapat menghambat pertumbuhan jamur Fusarium sp. JPTK1 yang ditunjukkan 
dengan diameter koloni yang berbeda nyata dengan kontrol dan antar perlakuan antagonis. Rerata diameter terendah dan penghambatan terbesar pada perlakuan Fusarium sp. JPTK1 vs Trichoderma sp. JRTK3 (Gambar 3 dan Tabel 1). Hasil uji menunjukkan bahwa perlakuan Fusarium sp. JPTK2 vs Aspergillus sp. JRTK1 dan perlakuan Fusarium sp. JPTK2 vs Penicillium sp. JRTK2 tidak berbeda nyata dengan kontrol Perlakuan Fusarium sp. JPTK2 vs Trichoderma sp. JRTK3 dengan menghasilkan penghambatan terbesar dengan rerata diameter koloni terendah yaitu 12,48 (Tabel 2).

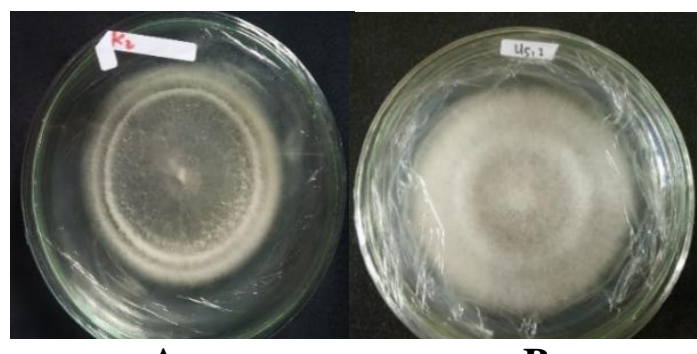

A

B

Gambar 1. Koloni jamur Fusarium sp. JPTK1 dan Fusarium sp. JPTK2 secara makroskopis pada media pda.

A. Koloni jamur Fusarium sp. JPTK1

B. Koloni jamur Fusarium sp. JPTK2

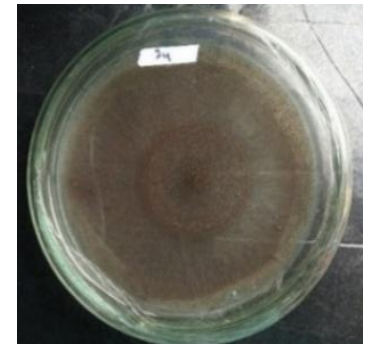

A

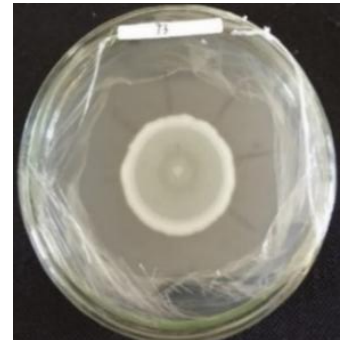

B

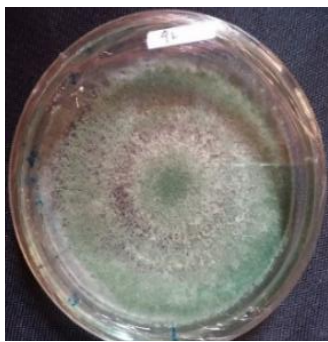

C

Gambar 2. Koloni jamur rizosfer secara makroskopis pada media pda

A. Koloni jamur Aspergillus sp. JRTK1

B. Koloni jamur Penicillium sp. JRTK2

C. Koloni jamur Trichoderma sp. JRTK3

Perlakuan uji antagonis masingmasing jenis jamur rizosfer berpengaruh nyata terhadap pertumbuhan jamur patogen Fusarium sp. JPTK1. Hasil uji lanjut menunjukkan bahwa masing-masing perlakuan pada uji antagonis berbeda nyata dengan kontrol dan beda nyata antar perlakuan. Perlakuan Fusarium sp. JPTK1 vs Trichoderma sp. JRTK3 berbeda nyata dengan kontrol dan perlakuan antagonis lainnya. Daya hambat tertinggi dengan rerata diameter koloni Fusarium sp. JPTK1 terkecil ditunjukkan pada perlakuan Fusarium sp. JPTK1 vs Trichoderma sp. JRTK3 yaitu 28,12 mm (Tabel 2).

Berdasarkan uji antagonis dapat dilihat kemampuan penghambatan dari masing-masing jamur rizosfer yang dinyatakan dalam persentase antagonis. Hasil uji antagonis ketiga 
jenis jamur rizosfer dengan Fusarium sp. JPTK1 menunjukkan rerata persentase antagonis tertinggi terlihat pada perlakuan Fusarium sp. JPTK1 vs Trichoderma sp. JRTK3 yaitu $37,12 \%$. Persentase terendah terlihat pada perlakuan antagonis Fusarium sp. JPTK1 vs Aspergillus sp. JRTK1 yaitu 10,58\% (Tabel 2).

Perlakuan uji antagonis masingmasing jenis jamur rizosfer berpengaruh nyata terhadap pertumbuhan jamur patogen Fusarium sp. JPTK2. Hasil uji lanjut menunjukkan bahwa perlakuan kontrol tidak berbeda nyata dengan perlakuan Fusarium sp. JPTK2 vs Aspergillus sp. JRTK1 dan Fusarium sp. JPTK2 vs Penicillium sp. JRTK2, tetapi berbeda nyata dengan perlakuan Fusarium sp. JPTK2 vs Trichoderma sp. JRTK3 Perlakuan Fusarium sp. JPTK2 vs Trichoderma sp. JRTK3 memberikan penghambatan terbesar terhadap pertumbuhan Fusarium sp. JPTK2 dengan nilai rerata diameter koloni jamur Fusarium sp. JPTK2 terendah yaitu $12,48 \mathrm{~mm}$. Hasil uji antagonis ketiga jenis jamur rizosfer dengan Fusarium sp. JPTK2 pada hari ke-7 menunjukkan rerata persentase antagonis tertinggi terlihat pada Fusarium sp. JPTK2 vs Trichoderma sp. JRTK3 yaitu 70,48\%. Persentase terendah terlihat pada Fusarium sp. JPTK2 vs Aspergillus sp. JRTK1 yaitu 4,73\% (Tabel 2).

Tabel 1. Rerata diameter koloni jamur Fusarium sp. JPTK1 hasil uji antagonis dengan 3 jenis jamur rizosfer pada hari ke- 7

\begin{tabular}{lcc}
\hline \multicolumn{1}{c}{ Perlakuan } & $\begin{array}{c}\text { Rerata Diameter } \\
\text { Koloni Jamur } \\
\text { Patogen } \\
(\mathbf{m m})\end{array}$ & $\begin{array}{c}\text { Rerata Persentase } \\
\text { Daya Antagonis } \\
\text { Jamur Rizosfer } \\
\text { Terhadap Jamur } \\
\text { Patogen (\%) }\end{array}$ \\
\hline $\begin{array}{l}\text { Kontrol Fusarium sp. JPTK1 } \\
\text { Fusarium sp. JPTK1 vs Aspergillus } \text { sp. }\end{array}$ & $44,72^{\mathrm{d}}$ & - \\
JRTK1 (P1 vs R1) & $39,99^{\mathrm{c}}$ & 10,58 \\
Fusarium sp. JPTK1 vs Penicillium sp. & $35,22^{\mathrm{b}}$ & 21,24 \\
JRTK2 (P1 vs R2) & $28,12^{\mathrm{a}}$ & 37,12 \\
Fusarium sp. JPTK1 vs Trichoderma sp. & & \\
JRTK3 (P1 vs R3) & & \\
\hline
\end{tabular}

Tabel 2. Rerata diameter koloni jamur Fusarium sp. JPTK2 (P2) hasil uji antagonis dengan 3 jenis jamur rizosfer pada Hari ke-7

\begin{tabular}{lcc}
\hline \multicolumn{1}{c}{ Perlakuan } & $\begin{array}{c}\text { Rerata Diameter } \\
\text { Koloni Jamur } \\
\text { Patogen } \\
(\mathbf{m m})\end{array}$ & $\begin{array}{c}\text { Rerata Persentase Daya } \\
\text { Antagonis Jamur } \\
\text { Rizosfer Terhadap } \\
\text { Jamur Patogen (\%) }\end{array}$ \\
\hline Kontrol Fusarium sp. JPTK2 & $42,27^{\mathrm{b}}$ & 4,73 \\
Fusarium sp. JPTK2 vs Aspergillus sp. & $40,27^{\mathrm{b}}$ & 4,78 \\
JRTK1 (P2 vs R1) & $40,25^{\mathrm{b}}$ & 70,48 \\
Fusarium sp. JPTK2 vs Penicillium sp. & $12,48^{\mathrm{a}}$ & \\
JRTK2 (P2 vs R2) & & \\
Fusarium sp. JPTK2 vs Trichoderma sp. & & \\
JRTK3 (P1 vs R3) & & \\
& & \\
\hline
\end{tabular}




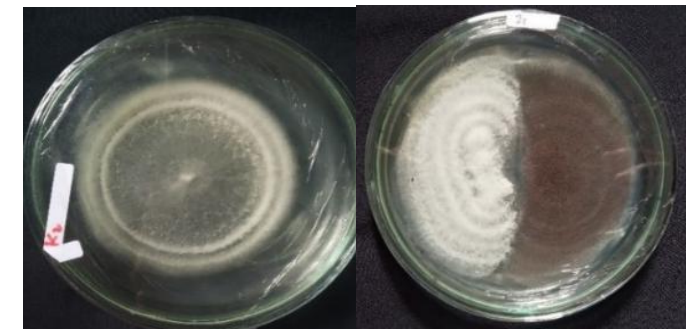

A

B

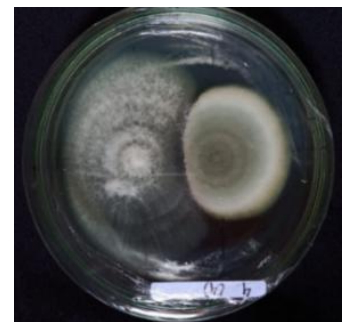

C

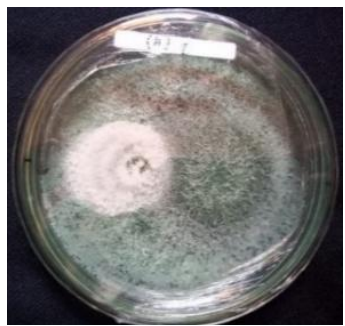

D

Gambar 3. Koloni Jamur Fusarium sp. JPTK1 dan Jamur Rizosfer pada Uji Antagonis Hari ke-7.

A. Kontrol Fusarium sp. JPTK1 (P1)

B. Koloni jamur Fusarium sp. JPTK1 vs Aspergillus sp. JRTK1 (P1 vs R1)

C. Koloni jamur Fusarium sp. JPTK1 vs Penicillium sp. JRTK2 (P1 vs R2)

D. Koloni jamur Fusarium sp. JPTK1 vs Trichoderma sp. JRTK3 (P1 vs R3)

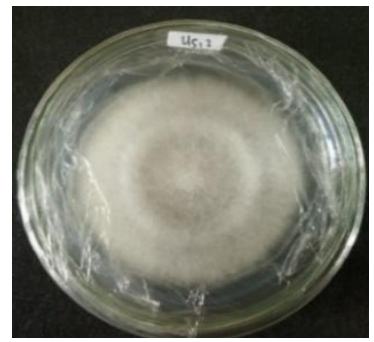

A

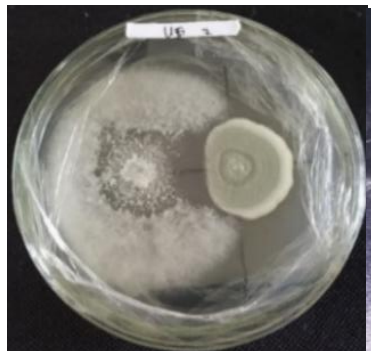

C

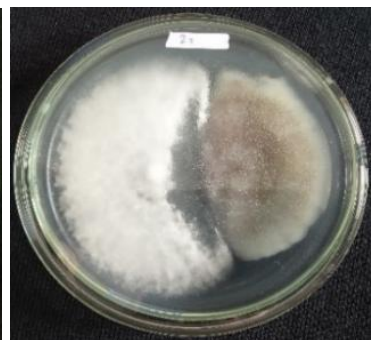

B

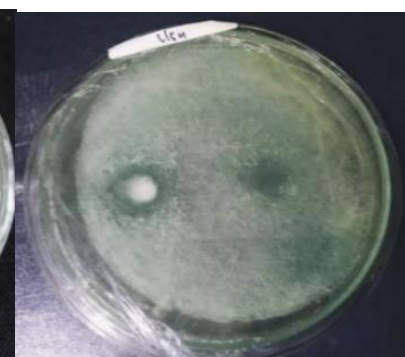

D

Gambar 4. Koloni jamur Fusarium sp. JPTK2 dan jamur rizosfer pada uji antagonis Hari ke-7.

A. Kontrol Fusarium sp. JPTK2 Permukaan Atas Koloni (P2)

B. Koloni jamur Fusarium sp. JPTK2 vs Aspergillus sp. JRTK1 Permukaan Atas Koloni (P2 vs R1)

C. Koloni jamur Fusarium sp. JPTK2 vs Penicillium sp. JRTK2 Pada Permukaan Atas Koloni (P2 vs R2)

D. Koloni jamur Fusarium sp. JPTK2 vs Trichoderma sp. JRTK3 Pada Permukaan Atas Koloni (P2 vs R3)

Jamur Trichoderma sp. JRTK3 memiliki daya antagonis tertinggi dibandingkan dengan jamur
Aspergillus sp. JRTK1 dan Penicillium sp. JRTK2 (Tabel 1 dan Tabel 2). Jamur Trichoderma sp. JRTK3 dapat 
tumbuh mencapai $90 \mathrm{~mm}$ pada hari ke 4, sementara jamur Aspergillus sp. JRTK1 dan Penicillium sp. JRTK2 tumbuh mencapai 75,73 $\mathrm{mm}$ dan 24,02 $\mathrm{mm}$ pada hari ke 4. Kondisi ini menunjukkan bahwa jamur Trichoderma sp. JRTK3 memiliki pertumbuhan yang lebih cepat dibandingkan jamur antagonis lainnya dan jamur Fusarium sp. JPTK1 dan Fusarium sp. JPTK2.

Rerata diameter koloni jamur Fusarium sp. JPTK1 pada perlakuan Fusarium sp. JPTK1 vs Trichoderma sp. JRTK3 lebih besar dibandingkan rerata diameter koloni jamur Fusarium sp. JPTK2 pada perlakuan Fusarium sp. JPTK2 vs Trichoderma sp. JRTK3 (Tabel 1 dan Tabel 2). Kondisi ini menunjukkan bahwa jamur patogen Fusarium sp. JPTK1 lebih mampu untuk melawan kekuatan antagonis dari jamur Trichoderma sp. JRTK3 dibandingkan jamur patogen Fusarium sp. JPTK2. Hal ini diduga pertahanan Fusarium sp. JPTK1 lebih kuat dibandingkan Fusarium sp. JPTK2 karena lapisan dinding sel Fusarium sp. JPTK1 lebih tebal dibandingkan lapisan dinding sel Fusarium sp. JPTK2. Imas dan Setiadi (1987) menyatakan dinding sel jamur Fusarium sp. mengandung kitin yang dilapisi oleh lapisan glukan sehingga dapat melindungi dari serangan jamur lainnya. Ketebalan lapisan glukan yang bervariasi pada spesies Fusarium sp. yang berbeda dapat menentukan kekuatan patogen bertahan pada jaringan inang.

Daya antagonis yang dihasilkan oleh Aspergillus sp. JRTK1 terhadap Fusarium sp. JPTK1 dan Fusarium sp. JPTK2 memiliki nilai yang berbedabeda. Daya antagonis yang dihasilkan Aspergillus sp. JRTK1 vs Fusarium sp. JPTK1 yaitu $10,58 \%$ sementara nilai persentase antagonis Aspergillus sp. JRTK1 vs Fusarium sp. JPTK2 yaitu 4,73\% (Tabel 1 dan Tabel 2). Perbedaan daya antagonis tersebut diduga dikarenakan jamur Fusarium sp. JPTK1 lebih cepat tumbuh dibandingkan dengan jamur Fusarium sp. Uji antagonis pada perlakuan Fusarium sp. JPTK1 vs Aspergillus sp. JRTK1 memperlihatkan adanya zona bening di antara kedua koloni jamur tersebut. Mekanisme antagonis dari jamur Aspergillus sp. JPTK3 vs Fusarium sp. JPTK1 diduga terjadi melalui mekanisme antibiosis.

Jamur genus Penicillium sp. JRTK2 mampu menghambat pertumbuhan jamur Fusarium sp. JPTK1 dengan daya antagonis jamur genus Penicillium sp. JRTK2 terhadap Fusarium sp. JPTK1 21,24\% hal ini dikarenakan jamur Penicillium sp. JRTK2 memiliki mekanisme antibiosis yang dapat menekan pertumbuhan jamur Fusarium sp. JPTK1 (Gambar 3). Mekanisme antibiosis Penicillium sp. JRTK2 ditandai dengan adanya perubahan pigmen warna pada permukaan bawah koloni jamur Penicillium sp. JRTK2 dan adanya zona bening di tengah-tengah koloni jamur Penicillium sp. JRTK2 vs Fusarium sp. JPTK1 (Gambar 4).

Jamur Penicillium sp. JRTK2 kurang mampu menghambat pertumbuhan jamur Fusarium sp. JPTK2 dan daya antagonisnya tidak berbeda nyata dengan perlakuan kontrol Fusarium sp. JPTK2 yaitu dengan nilai 4,73\% (Tabel 2). Hal ini diduga terjadi karena cepatnya pertumbuhan Fusarium sp. JPTK2 dibandingkan pertumbuhan jamur Penicillium sp. JRTK2 (Gambar 4) sehingga jamur Fusarium sp. JPTK2 lebih banyak mendapatkan ruang dan nutrisi dibandingkan dengan jamur Penicillium sp. JRTK2. Kurangnya kemampuan jamur Penicillium sp. 
JRTK2 untuk berkompetisi memperebutkan nutrisi menyebabkan jamur tersebut menggunakan pertahanan dengan menghasilkan metabolit sekunder berupa pigmen warna dan adanya zona bening yang dapat menekan pertumbuhan jamur Fusarium sp. JPTK2.

Menurut Isaac (1994) beberapa jenis jamur memang mampu menghasilkan metabolit sekunder berupa pigmen warna. Kondisi dan nutrisi yang tidak menguntungkan menyebabkan beberapa jamur menghasilkan metabolit sekunder berupa pigmen warna. Sudarma et al. (2015) menyatakan faktor-faktor yang menyebabkan jamur memproduksi metabolit sekunder berupa pigmen warna dipengaruhi oleh nutrisi, $\mathrm{pH}$, suhu dan waktu inkubasi.

\section{KESIMPULAN}

Berdasarkan hasil penelitian, maka dapat disimpulkan bahwa hasil isolasi dan identifikasi jamur patogen dari buah kopi (Coffea sp.) bergejala busuk ditemukan 2 jenis jamur, yaitu Fusarium sp. JPTK1 dan Fusarium sp. JPTK2. Hasil isolasi dan identifikasi jamur rizosfer dari perakaran tanaman kopi (Coffea sp.) ditemukan 3 jenis jamur, yaitu Aspergillus sp. JRTK1, Penicillium sp. JRTK2, Trichoderma sp. JRTK3. Berdasarkan tingkat antagonisnya, jamur rizosfer yang memiliki daya antagonis tertinggi dalam menekan pertumbuhan Fusarium sp. JPTK1 dan Fusarium sp. JPTK2 adalah Trichoderma sp. JRTK3 masing-masing sebesar $37,12 \%$ dan $70,48 \%$.

\section{DAFTAR PUSTAKA}

Barnet HL \& BB Hunter (1972) Ilustrated Genera of Imperfect Fungi, Third edition.
Minneeapolis, Burges Publishing Company

Djafarudin (2004) Dasar-Dasar Pengendalian Penyakit Tanaman, Bumi Aksara, Jakarta

Fety KS \& Mukarlina (2015) Uji Antagonis Jamur Rizosfer Isolat Lokal terhadap Phytophthora sp. yang Diisolasi dari Batang Langsat (Lansium domesticum Corr.), Protobiont Vol. 4, No. 1, Hal. 2-8.

Fitriah B, Irwan, L \& Johanes, P (2014) Eksplorasi Bakteri Endofit Sebagai Agens Pengendalian Hayati Terhadap Penyakit Darah Pada Tanaman Pisang Secara InVitro, Jurnal Agrotekbis Vol. 2, No. 6, Hal. 579-586.

Gilang, R (2015) Penapisan Jamur Antagonis Indigenus Rizosfer Kakao (Theobroma Cacao Linn.) Yang Berpotensi Menghambat Pertumbuhan Jamur Phytophthora Palmivora Butler. Skripsi. Fakultas Pertanian, Universitas Andalas. Padang.

Imas T \& Setiadi, Y (1987) Mikrobiologi Tanah. Pusat Antar Institut Pertanian Bogor. Bogor.

Isaac S (1994) Many fungi are brightly coloured Does pigmentation provide any advantageto those species, Mycology answer. Departement of Genetics \& Microbiology. University of Liverpool. Liverpool.

Rianti R, Khotimah S \& Mukarlina (2010) Uji Antagonis Trichoderma harzianum Terhadap Fusarium spp. Penyebab Penyakit Layu pada Tanaman Cabai, Jurnal Fitomedika Vol. 7, No. 2, Hal 3.

Rudy SU (2014) Kelayakan Industri Kopi Di Provinsi Kalimantan Barat, Jurnal Bina Praja Vol. 6, No. 3, Hal. 2.

Samson RA, Houbraken J, Thrane JC, Frisvad, \& Andersen F (2010) 
Food and Indoor Fungi. Fungal Biodiversity Centre Utrecht. Netherlends.

Sari M, Yulianty, \& Martha LL (2013)

Keanekaragaman Jenis Jamur Pada

Tanaman Kopi (Coffea spp.) di Bandar Lampung, Jurnal Ilmiah Vol. 1, No. 1, Hal 1.

Soesanto L (2008) Pengantar

Pengendalian Hayati Penyakit

Tanaman. Rajawali Press. Jakarta

Sudarma AGDI, Sastrawidana KDI,

Maryam S (2015) Produksi

Pigmen Warna Merah dari Jamur Penicillium Purpurogenum yang diisolasi dari Tanah Tercemar Limbah Susu Kambing dengan Metode Submerged Fermentation, Jurnal Proscedings Seminar Nasional, FMIPA Undiksha 5, Hal 4.

Sutton (1990) A Guide Tropical Fungi,Singapore Science Cemter. Singapore.

Waluyo L (2008) Mikrobiologi Umum, UMM Press. Malang.

Watanabe T (1937) Morphologies of Cultured Fungi and Key Species. United State of America. Newyork. 